\title{
ROZWIĄZANIE ZAGADNIENIA ODWROTNEGO Z NUMERYCZNYM CAŁKOWANIEM SPLOTU
}

\begin{abstract}
W pracy rozwiązano zagadnienie odwrotne dla liniowego, niestacjonarnego równania przewodnictwa ciepła w walcu. Rozwiązanie otrzymano z zastosowaniem transformaty Laplace'a oraz przedstawiono w postaci splotu funkcji. W całkowaniu splotu zastosowano parametr $\Theta$ oraz zbadano wpływ wartości tego parametru na wrażliwość rozwiązania zagadnienia odwrotnego. W badaniach uwzględniono wpływ błędu zabudowy termoelementu oraz stochastycznego błędu pomiaru temperatury na błąd rozkładu temperatury na brzegu walca.
\end{abstract}

Słowa kluczowe: zagadnienie odwrotne, przewodnictwo cieplne, wrażliwość rozwiązania

\section{Wstęp}

Procesy nagrzewania elementów maszyn, czy procesy obróbki cieplnej wymagają realizacji pola temperatury spełniającego zadane kryteria. W celu sterowania nagrzewaniem ciała bardzo ważna jest znajomość temperatury brzegu obszaru. Pomiar temperatury brzegu nie zawsze jest możliwy do przeprowadzenia na przykład w komorze spalania czy na powierzchni wewnętrznej korpusu turbiny cieplnej. W szczególności jest to trudne, jeśli duży udział w procesie nagrzewania ma promieniowanie (procesy obróbki cieplnej) [16]. W takich przypadkach temperaturę brzegu można określić z rozwiązania zagadnienia odwrotnego $\mathrm{w}$ oparciu o pomiar temperatury w punktach wewnętrznych ciała umieszczonych blisko brzegu, na którym nie jest znany przebieg temperatury [3, $6,14]$. Niektóre metody rozwiązywania jednowymiarowego zagadnienia odwrotnego rozkładu pól temperatury dla walca przedstawiono w pracy [5], natomiast dla warstwy cylindrycznej w pracy [4]. Rozkłady temperatury w walcu z użyciem zagadnienia prostego i odwrotnego badano również za pomocą funkcji cieplnych [13]. Rozwiązanie zagadnienia odwrotnego w oparciu o transformatę Laplace'a przedstawiono w pracach $[4,5,8-10]$. Zagadnienie odwrotne dla rów-

\footnotetext{
1 Autor do korespondencji/corresponding author: Magda Joachimiak, Politechnika Poznańska, 60-965 Poznań, ul. Piotrowo 3, tel.: (61) 66522 14, e-mail: magda.joachimiak@put.poznan.pl

${ }^{2}$ Michał Ciałkowski, Politechnika Poznańska, e-mail: michal.cialkowski@put.poznan.pl
} 
nania przewodnictwa ciepła rozwiązano przy użyciu metody sekwencyjnej, co opisano w pracach $[2,15]$.

W pracy opisano rozwiązanie zagadnienia prostego i odwrotnego dla niestacjonarnego równania przewodnictwa ciepła oraz przeanalizowano wrażliwość otrzymanych wyników na błędy zabudowy termoelementu oraz stochastyczny błąd pomiaru temperatury. Znaczne koszty zabudowy wielu termoelementów wewnątrz obszaru walca skłoniły autorów do przebadania wpływu błędu zabudowy pojedynczego termoelementu i stochastycznego błędu pomiaru temperatury na stabilność wyznaczenia pola temperatury w badanym obszarze.

\section{Zagadnienie proste}

Równanie liniowe niestacjonarnego przewodnictwa ciepła dla symetrycznego pola temperatury w walcu można zapisać w następującej postaci [7]:

- równanie różniczkowe

$$
\frac{\partial \vartheta}{\partial \tau}=\frac{\partial^{2} \vartheta}{\partial \xi^{2}}+\frac{1}{\xi} \frac{\partial \vartheta}{\partial \xi} \xi \in(0,1), \tau>0
$$

- warunek początkowy

$$
\vartheta(\xi, \tau=0)=0
$$

- warunek brzegowy

$$
\vartheta(\xi=1, \tau)=\vartheta_{z}(\tau) \quad \tau>0
$$

- warunek ograniczoności rozwiązania w punkcie $\xi=0$

$$
|\vartheta(\xi=0, \tau)|<\infty
$$

Zależności (1) - (4) przedstawiono w postaci bezwymiarowej z uwzględnieniem zależności [5]

$$
\xi=\frac{r}{r_{z}}, \vartheta=\frac{T-T_{0}}{T_{\max }}, \tau=\frac{\lambda}{\rho c} \frac{t}{r_{z}^{2}}
$$

Do rozwiązania zagadnienia (1) - (4) zastosowano przekształcenie Laplace'a [7,11], warunki (2) - (4) [7,11,12], twierdzenie Borela o splocie [11], twierdzenie o residuach [7], regułę de L’Hospitala oraz własności dla zmodyfikowanych funkcji Bessela [7, 12]. Zatem symetryczne pole temperatury w walcu wyraża się w postaci splotu funkcji $[9,10]$ : 


$$
\begin{aligned}
& \vartheta(\xi, \tau)=\frac{\partial \vartheta(\xi=1, \tau)}{\partial \tau} *\left[1-2 \sum_{n=1}^{\infty} \frac{J_{0}\left(p_{n} \xi\right) e^{-p_{n}^{2} \tau}}{p_{n} J_{1}\left(p_{n}\right)}\right]=\frac{\partial \vartheta(\xi=1, \tau)}{\partial \tau} * \vartheta_{w}(\xi, \tau)= \\
& =\vartheta(\xi=1, \tau) *\left[2 \sum_{n=1}^{\infty} \frac{J_{0}\left(p_{n} \xi\right) p_{n} e^{-p_{n}^{2} \tau}}{J_{1}\left(p_{n}\right)}\right]=\vartheta(\xi=1, \tau) * \frac{\partial \vartheta_{w}(\xi, \tau)}{\partial \tau}
\end{aligned}
$$

Funkcja $\vartheta_{w}(\xi, \tau)$ jest rozwiązaniem równania (1) z warunkiem początkowym (2) i stałą temperaturą na brzegu $\vartheta_{w}(\xi=1, \tau)=1$ (warunek (3), $\vartheta_{z}=1$ ).

\section{Zagadnienie odwrotne}

Ponieważ nie zawsze jest możliwe określenie temperatury na brzegu obsza$\mathrm{ru}$, określenia temperatury brzegu można dokonać rozwiązując zagadnienie odwrotne (brzegowe zagadnienie odwrotne). W tym celu należy dokonać pomiaru temperatury w punktach wewnętrznych obszaru (rys. 1). W następnym kroku poszukuje się wartości funkcji $\vartheta(\xi=1, \tau)$ z minimalizacji odległości pomiędzy temperaturą wyrażoną wzorem (6), a wartością pomierzoną dla kolejnych chwil czasu . Termoelement umieszczony jest w odległości $g=r_{z}-r^{*}$ od brzegu walca, stąd bezwymiarowa współrzędna $\xi^{*}=\frac{r^{*}}{r_{z}}$.

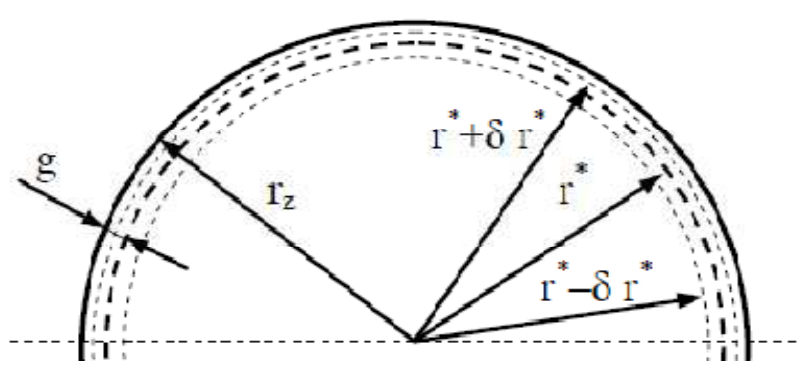

Rys. 1. Rysunek przekroju poprzecznego walca z zaznaczonym promieniem zewnętrznym $\left(\mathrm{r}_{\mathrm{z}}\right)$, punktem zabudowy termoelementu $\left(r^{*}, g\right)$ oraz dokładnością umiejscowienia termoelementu $\left(\mathrm{r}^{*}+\delta \mathrm{r}^{*}, \mathrm{r}^{*}-\delta \mathrm{r}^{*}\right)$

Fig. 1. Figure of a cylinder cross-section with the outer radius $\left(\mathrm{r}_{\mathrm{z}}\right)$, the point of thermocouple installation $\left(\mathrm{r}^{*}, \mathrm{~g}\right)$ and the accuracy of the thermocouple location $\left(r^{*}+\delta r^{*}, r^{*}-\delta r^{*}\right)$. 
Rozwiązanie splotowe (dla pojedynczego termoelementu) dla miejsca pomiaru temperatury $r=r^{*} \quad\left(\xi=\xi^{*}\right)$ jest równe wartości zmierzonej, zatem dla dwóch kolejnych chwil czasu $\tau_{i}, \tau_{i+1}$ mamy:

$$
\begin{aligned}
& \left\{\begin{array}{c}
\vartheta\left(\xi^{*}, \tau_{i}\right)=\int_{0}^{\tau_{i}} \vartheta^{\prime}(\xi=1, u) \vartheta_{w}\left(\xi^{*}, \tau_{i}-u\right) d u \\
\vartheta\left(\xi^{*}, \tau_{i+1}\right)=\int_{0}^{\tau_{i+1}} \vartheta^{\prime}(\xi=1, u) \vartheta_{w}\left(\xi^{*}, \tau_{i+1}-u\right) d u
\end{array}\right.
\end{aligned}
$$

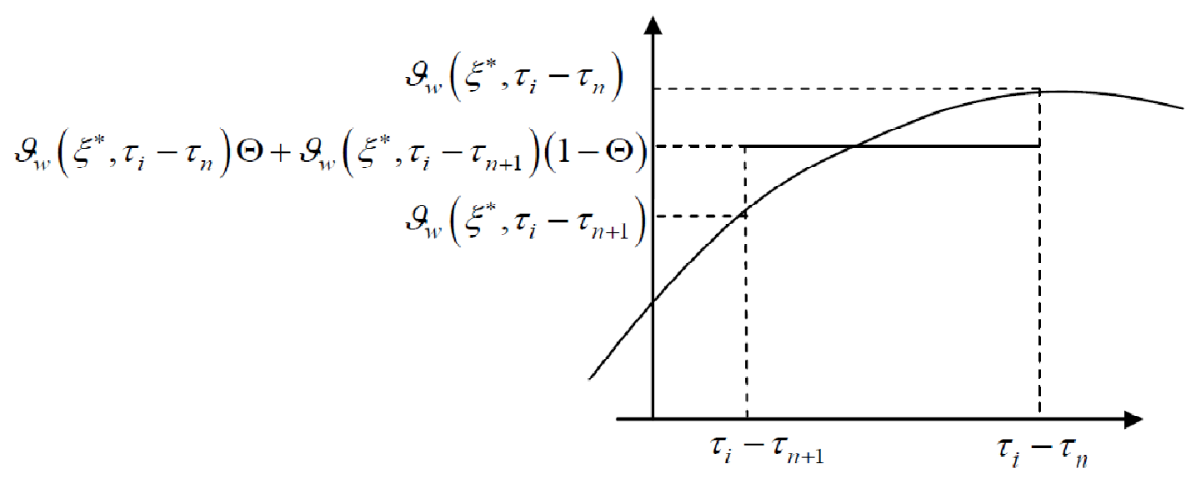

Rys. 2. Aproksymacja funkcji $\vartheta_{\mathrm{w}}$ funkcją schodkową

Fig. 2. Approximation of the function $\vartheta_{w}$ by the staircase function

Ponieważ funkcja $\vartheta_{w}\left(\xi^{*}, \tau_{i}-u\right)>0$ przeto dla uproszczenia całkowania splotu funkcję $\vartheta_{w}$ przybliżono funkcją schodkową [1] (rys. 2). Po przekształceniach opisanych w pracach $[9,10]$ otrzymano dla $i>1$ układ równań z macierzą trójkątną:

$$
\left[\begin{array}{ccccc}
a_{11} & 0 & \ldots & \ldots & 0 \\
a_{21} & a_{22} & \ddots & & \vdots \\
a_{31} & a_{32} & a_{33} & \ddots & \vdots \\
\vdots & \vdots & \vdots & \ddots & 0 \\
a_{i 1} & a_{i 2} & a_{i 3} & \ldots & a_{i i}
\end{array}\right]\left\{\begin{array}{c}
\chi_{1} \\
\chi_{2} \\
\chi_{3} \\
\vdots \\
\chi_{i}
\end{array}\right\}=\left\{\begin{array}{c}
B_{1} \\
B_{2} \\
B_{3} \\
\vdots \\
B_{i}
\end{array}\right\}
$$

gdzie:

$$
a_{i+1, i+1}=\left[\vartheta_{w}\left(\xi^{*}, \tau_{i+1}-\tau_{i}\right) \Theta+\vartheta_{w}\left(\xi^{*}, \tau_{i+1}-\tau_{i+1}\right)(1-\Theta)\right]\left(\tau_{i+1}-\tau_{i}\right)
$$




$$
\begin{aligned}
& \chi_{i+1}=\vartheta\left(\xi=1, \tau_{i+1}\right)-\vartheta\left(\xi=1, \tau_{i}\right), i=0,1,2, \ldots \\
& a_{i, n}=\left\{\vartheta_{w}\left(\xi^{*}, \tau_{i+1}-\tau_{n}\right) \Theta+\vartheta_{w}\left(\xi^{*}, \tau_{i+1}-\tau_{n+1}\right)(1-\Theta)-\right. \\
& \left.-\left[\vartheta_{w}\left(\xi^{*}, \tau_{i}-\tau_{n}\right) \Theta+\vartheta_{w}\left(\xi^{*}, \tau_{i}-\tau_{n+1}\right)(1-\Theta)\right]\right\}\left(\tau_{n+1}-\tau_{n}\right) \\
& i \geq 1, n=0,1, \ldots, i-1 \\
& B_{j}=\frac{\vartheta\left(\xi^{*}, \tau_{j+1}\right)-\vartheta\left(\xi^{*}, \tau_{j}\right)}{\tau_{j+1}-\tau_{j}}, j=0,1, \ldots, i-1
\end{aligned}
$$

lub w zwartej formie (dla stałego kroku czasowego $\Delta \tau=\tau_{i+1}-\tau_{i}$ )

$$
\left[A\left(\Theta, \vartheta_{w}\left(\xi^{*}\right), \Delta \tau\right)\right]\{\chi\}=\left\{B\left(\vartheta\left(\xi^{*}\right), \Delta \tau\right)\right\}
$$

Zatem jeśli istnieje macierz odwrotna $A^{-1}$, to

$$
\{\chi\}=\left[A\left(\Theta, \vartheta_{w}\left(\xi^{*}\right), \Delta \tau\right)\right]^{-1}\left\{B\left(\vartheta\left(\xi^{*}\right), \Delta \tau\right)\right\}
$$

\section{Wrażliwość rozwiązania zagadnienia odwrotnego na błędy pomiarowe}

Każde równanie macierzowe postaci $A \chi=B$ można scharakteryzować za pomocą jego wrażliwości. Wrażliwość rozwiązania opisuje wpływ zaburzenia danych definiujących problem, tj. macierzy $\mathrm{A}$ i wektora $\mathrm{B}$, na wartość rozwiązania $\chi$. W obiczeniach uwzględniono błąd umiejscowienia termoelementu (macierz A traktujemy jako niezaburzoną). Założono, że termoelement może znajdować się w punktach $\xi=\xi^{*} \pm \delta \xi^{*}$, gdzie $\delta \xi^{*}=\frac{\delta r^{*}}{r_{z}}$. Pomiar temperatury obarczony jest losowym błędem, który jest funkcją czasu, oznaczamy go $\delta \vartheta\left(\xi^{*}, \tau_{i}\right)$. Funkcja ta przyjmuje wartości $\delta \vartheta\left(\xi^{*}, \tau_{i}\right) \in\left\langle-\frac{\delta T^{*}}{T_{\max }}, \frac{\delta T^{*}}{T_{\max }}\right\rangle$. Na podstawie wzorów (8) - (12) wyznaczono rozkład temperatury na brzegu walca przy wystąpieniu błędu zabudowy termoelementu i stochastycznego błędu pomiaru temperatury. 


$$
\begin{aligned}
& {\left[A\left(\Theta, \vartheta_{w}\left(\xi^{*}\right), \Delta \tau\right)\right]\left\{\chi+\delta \chi\left(\delta \xi^{*}, \delta \vartheta, \tau\right)\right\}=} \\
& =\left\{B\left(\vartheta\left(\xi^{*}\right), \tau\right)+\delta B\left(\delta \xi^{*}, \delta \vartheta, \tau\right)\right\}
\end{aligned}
$$

Wówczas po odjęciu (13) od (15) mamy, że

$$
\left[A\left(\Theta, \vartheta_{w}\left(\xi^{*}\right), \Delta \tau\right)\right]\left\{\delta \chi\left(\delta \xi^{*}, \delta \vartheta, \tau\right)\right\}=\left\{\delta B\left(\delta \xi^{*}, \delta \vartheta, \tau\right)\right\}
$$

Zatem wektor rozkładu zaburzenia temperatury

$$
\left\{\delta \chi\left(\delta \xi^{*}, \delta \vartheta, \tau\right)\right\}=\left[A\left(\Theta, \vartheta_{w}\left(\xi^{*}\right), \Delta \tau\right)\right]^{-1}\left\{\delta B\left(\delta \xi^{*}, \delta \vartheta, \tau\right)\right\}
$$

gdzie, na podstawie (12), mamy

$$
\begin{aligned}
& \delta B_{j}\left(\delta \xi^{*}, \delta \vartheta\right)= \\
& =\frac{\vartheta\left(\xi^{*} \pm \delta \xi^{*}, \tau_{j+1}\right)+\delta \vartheta\left(\xi^{*}, \tau_{j+1}\right)-\left(\vartheta\left(\xi^{*} \pm \delta \xi^{*}, \tau_{j}\right)+\delta \vartheta\left(\xi^{*}, \tau_{j}\right)\right)}{\tau_{j+1}-\tau_{j}}- \\
& -\frac{\vartheta\left(\xi^{*}, \tau_{j+1}\right)-\vartheta\left(\xi^{*}, \tau_{j}\right)}{\tau_{j+1}-\tau_{j}}, \quad j=0,1, \ldots, i-1
\end{aligned}
$$

\section{Przykład numeryczny}

Przykładowe obliczenia wykonano dla walca o promieniu $r_{z}=50 \mathrm{~mm}$, wykonanego ze stali niskowęglowej dla której gęstość $\rho=7841 \mathrm{~kg} / \mathrm{m}^{3}$, cieplo wlaściwe $\mathrm{c}=456 \mathrm{~J} /(\mathrm{kgK})$ oraz współczynnik przewodzenia ciepła $\lambda=50,3$ $\mathrm{W} /(\mathrm{mK})$. Założono, dla przetestowania programu, że bezwymiarowy rozkład temperatury na brzegu elementu wyrażony jest za pomocą funkcji wykładniczej $f(\tau)=1-e^{-\beta \tau}$ gdzie, $\beta$ jest współczynnikiem określającym tempo nagrzewania i dla analizowanego przykładu przyjęto $\beta=1,5$. Przyjęte wartości odpowiadają przebiegom nagrzewania elementów w wielu procesach przemysłowych $\mathrm{np}$. w procesie azotowania, a czas nagrzewania brzegu walca $t=680 \mathrm{~s}$. Założono, że termoelement znajduje się $2 \mathrm{~mm}$ od brzegu walca, czyli na promieniu $r^{*}=r_{z}-2 \mathrm{~mm}=48 \mathrm{~mm}\left(\xi^{*}=0,96\right)$. Założono, że dokladność zabudowy termoelementu wynosi $\pm 0,5 \mathrm{~mm}$, a pomiar wykonywany jest z dokladnością 2,2 ${ }^{\circ} \mathrm{C}$. W analizowanym przykładzie przyjęto wartości parametru całkowania splotu $\Theta=0,5 ; \Theta=0,51$ oraz $\Theta=0,52$.

Rozkłady temperatury na brzegu elementu obliczone za pomocą zagadnienia prostego oraz zagadnienia odwrotnego z uwzględnieniem losowego 
zaburzenia pomiaru temperatury przedstawiono na rysunku 3. Dla $\Theta=0,5$ różnica między założoną temperaturą na brzegu oraz obliczoną za pomocą metody zagadnienia odwrotnego sięga ponad $120{ }^{\circ} \mathrm{C}$ oraz wzrasta dla kolejnych jednostek czasu (rys. 3 a).

Znaczny wzrost błędu rozwiązania można zauważyć już po upływie 230 sekund od rozpoczęcia procesu nagrzewania. Wraz ze wzrostem $\Theta$ od wartości 0,5 do 0,52 odchylenie wartości obliczonych za pomocą zagadnienia odwrotnego od założonej funkcji rozkładu temperatury na brzegu walca znacznie maleje (rys. 3). Przy jednoczesnym uwzględnieniu błędu zabudowy termoelementu oraz stochastycznego zaburzenia pomiaru temperatury różnica pomiędzy obliczonymi, a założonymi wartościami temperatury na brzegu maleje ze wzrostem $\Theta$ od wartości 0,5 do 0,52 (rys. 4, 5). Zatem odpowiedni dobór $\Theta$ znacząco wpływa na wrażliwość rozwiązania.

Rys. 3. Rozkład temperatury na brzegu walca obliczony na podstawie rozwiązania zagadnienia prostego (zp), zagadnienia odwrotnego $\mathrm{z}$ uwzględnieniem losowego zaburzenia temperatury (zo_ran) dla $\beta=1,5 ; \mathrm{t}=680 \mathrm{~s} ; \mathrm{r}_{\mathrm{z}}=50$ $\mathrm{mm}$, termoelementu umieszczonego $\mathrm{g}=2 \mathrm{~mm}$ od brzegu oraz a) $\Theta=0,5$ b) $\Theta=$ 0,51 c) $\Theta=0,52$

Fig. 3. Distribution of temperature on the edge of the cylinder calculated on the basis of solving the direct problem (zp), the inverse problem with random disturbance of temperature (zo_ran) for $\beta=1.5 ; \mathrm{t}=680 \mathrm{~s} ; \mathrm{r}_{\mathrm{z}}$ $=50 \mathrm{~mm}$, the thermocouple located $\mathrm{g}=2 \mathrm{~mm}$ from the edge and for: a) $\Theta=0.5$, b) $\Theta=0.51$ and c) $\Theta=0.52$. a)
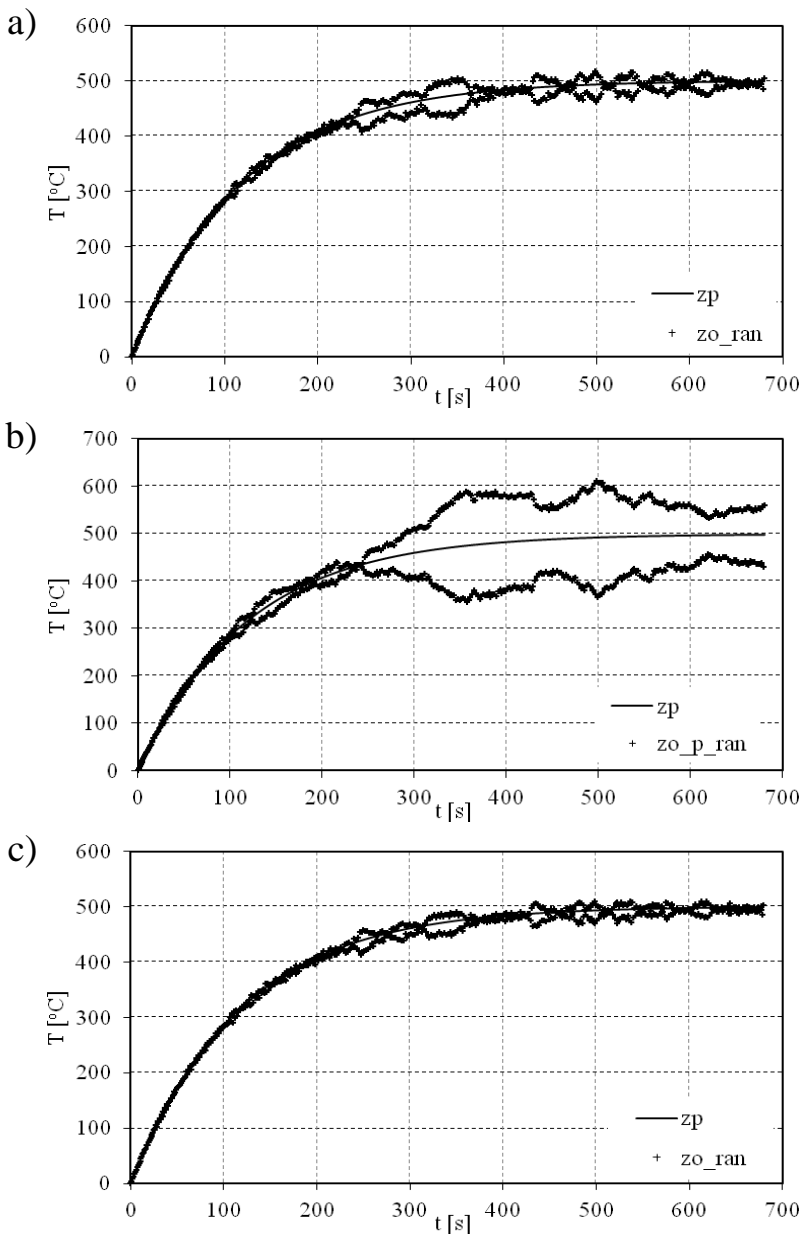
a)

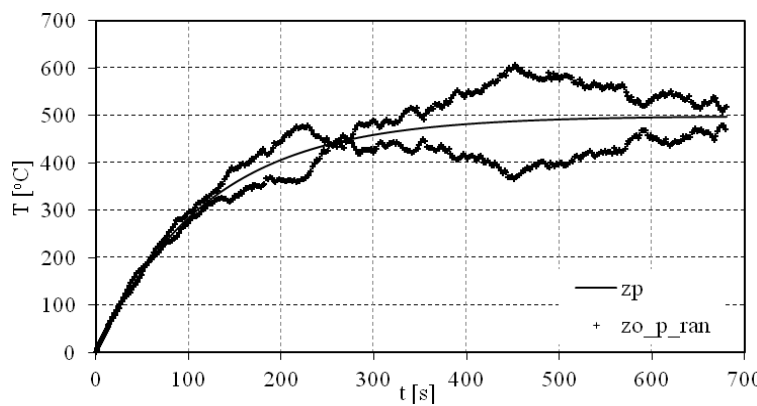

b)

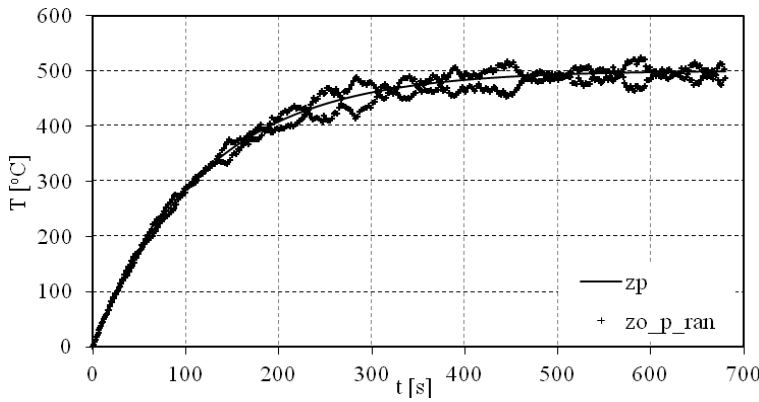

c)

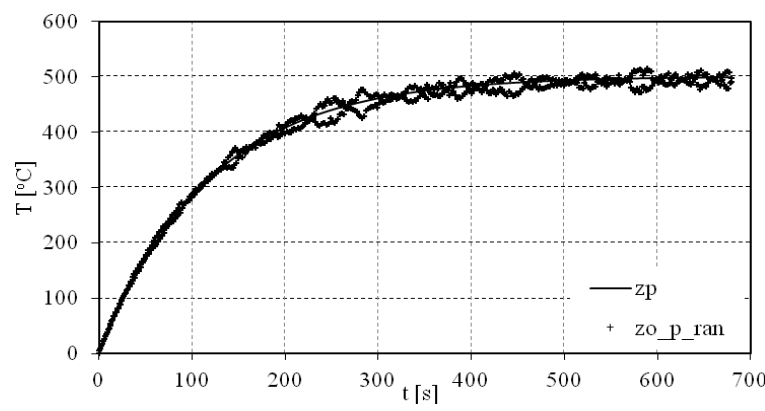

Rys. 4. Rozkład temperatury na brzegu walca obliczony na podstawie rozwiązania zagadnienia prostego (zp), zagadnienia odwrotnego $\mathrm{z}$ uwzględnieniem błędu położenia termoelementu ( $\left.r=r^{*}+\delta r^{*}\right) \quad$ i losowego zaburzenia temperatury (zo_p_ran) dla $\beta=1,5 ; \mathrm{t}=680$ $\mathrm{s} ; \mathrm{r}_{\mathrm{z}}=50 \mathrm{~mm}$, termoelementu umieszczonego $\mathrm{g}=2 \mathrm{~mm}$ od brzegu oraz a) $\Theta=0,5$ b) $\Theta=$ 0,51 c) $\Theta=0,52$

Fig. 4. Distribution of temperature on the edge of the cylinder calculated on the basis of solving the direct problem (zp), the inverse problem with the error of the thermocouple location ( $r=r^{*}+\delta r^{*}$ ) and random disturbance of temperature (zo_p_ran) for $\beta=1.5 ; \mathrm{t}=680$ $\mathrm{s} ; \mathrm{r}_{\mathrm{z}}=50 \mathrm{~mm}$, the thermocouple located $\mathrm{g}=2 \mathrm{~mm}$ from the edge and for: a) $\Theta=0.5, b) \Theta=0.51$ and c) $\Theta=0.52$

Maksymalny błąd uzyskanego rozwiązania w znacznym stopniu zależy od wartości $\Theta$. Dla $\Theta<0,5$ rozwiązanie jest niestabilne. Natomiast dla $0,5 \leq \Theta \leq 1$ różnica pomiędzy temperaturą na brzegu obliczoną na podstawie rozwiązania zagadnienia prostego i odwrotnego wzrasta (rys. 6) do $2,2{ }^{\circ} \mathrm{C}$. Rozkład temperatury na brzegu przy uwzględnieniu błędu zabudowy $r=r^{*}+\Delta r^{*}$ najpierw maleje, a dla $\Theta>0,8$ wzrasta osiągając do $2,2{ }^{\circ} \mathrm{C}$. Przy przesunięciu termoelementu $\mathrm{W}$ kierunku środka walca dla wzrastających wartości $\Theta$ błąd także wzrasta do $3,8^{\circ} \mathrm{C}$. Na rysunku 7 pokazano zależność przedstawiajacą maksymalne błędy rozwiązania podczas obliczeń uwzględniajacych stochastyczne zaburzenie pomiaru temperatury przy jednoczesnym uwzględnieniu błędu zabudowy. Wraz ze wzrostem $\Theta$ od wartości 0,5 do 1 błąd maleje od blisko $120{ }^{\circ} \mathrm{C}$ do $6{ }^{\circ} \mathrm{C}$. Najszybszy spadek występuje dla $0,5 \leq \Theta \leq 0,51$ (rys. $7 \mathrm{c}$ ). 
a)

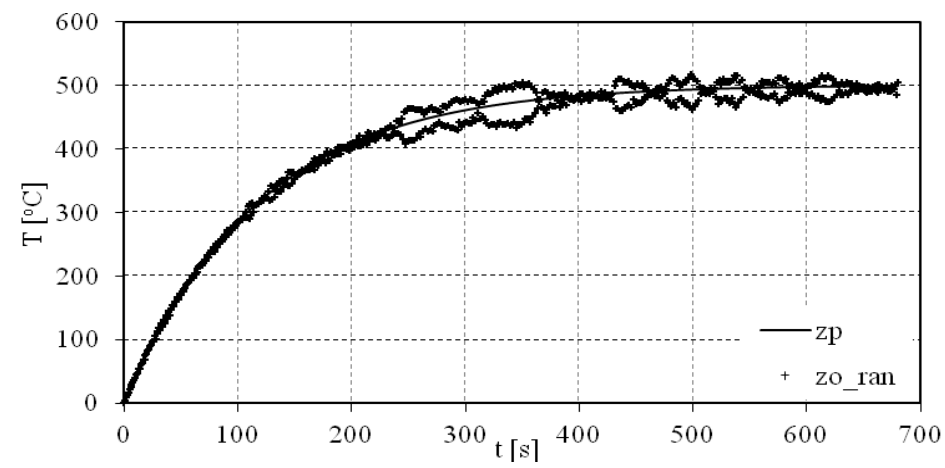

b)

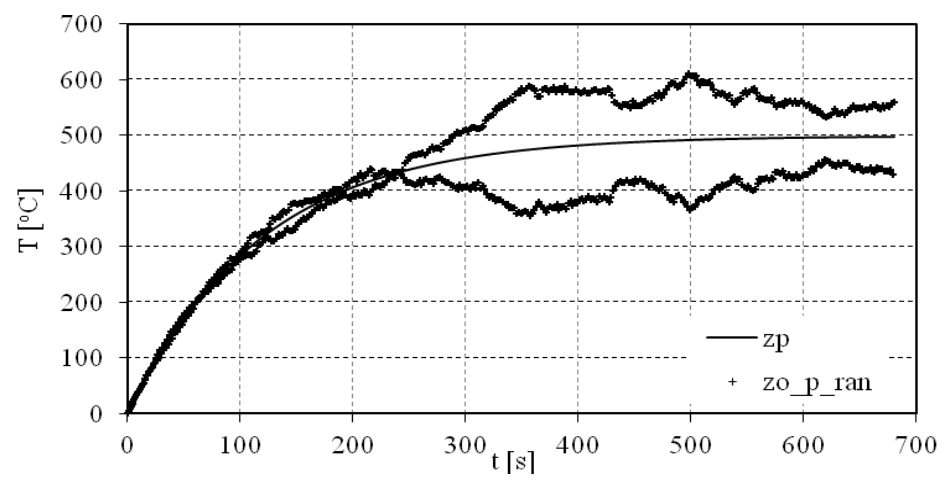

c)

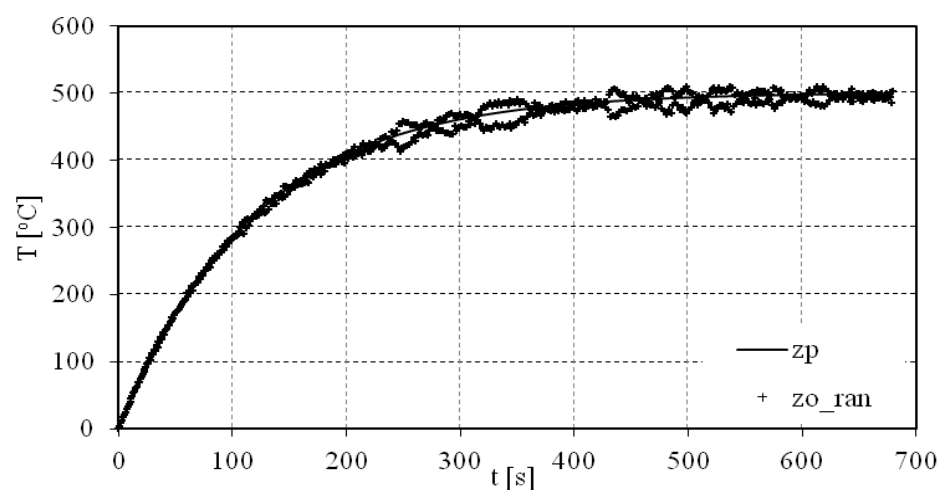

Rys. 5. Rozkład temperatury na brzegu walca obliczony na podstawie rozwiązania zagadnienia prostego (zp), zagadnienia odwrotnego $\mathrm{z}$ uwzględnieniem błędu położenia termoelementu $r=r^{*}-\delta r^{*}$ ) i losowego zaburzenia temperatury (zo_m_ran) dla $\beta=1,5 ; \mathrm{t}=680 \mathrm{~s} ; \mathrm{r}_{\mathrm{z}}=50 \mathrm{~mm}$, termoelementu umieszczonego $\mathrm{g}=2$ mm od brzegu oraz a) $\Theta=0,5$ b) $\Theta=0,51$ c) $\Theta=0,52$

Fig. 5. Distribution of temperature on the edge of the cylinder calculated on the basis of solving the direct problem (zp), the inverse problem with the error of the thermocouple location $\left(r=r^{*}-\delta r^{*}\right)$ and random disturbance of temperature (zo_m_ran) for $\beta=1.5 ; \mathrm{t}=680 \mathrm{~s} ; \mathrm{r}_{\mathrm{z}}=50 \mathrm{~mm}$, the thermocouple located $\mathrm{g}=2 \mathrm{~mm}$ from the edge and for: a) $\Theta=0.5$, b) $\Theta=0.51$ and c) $\Theta=0.52$ 

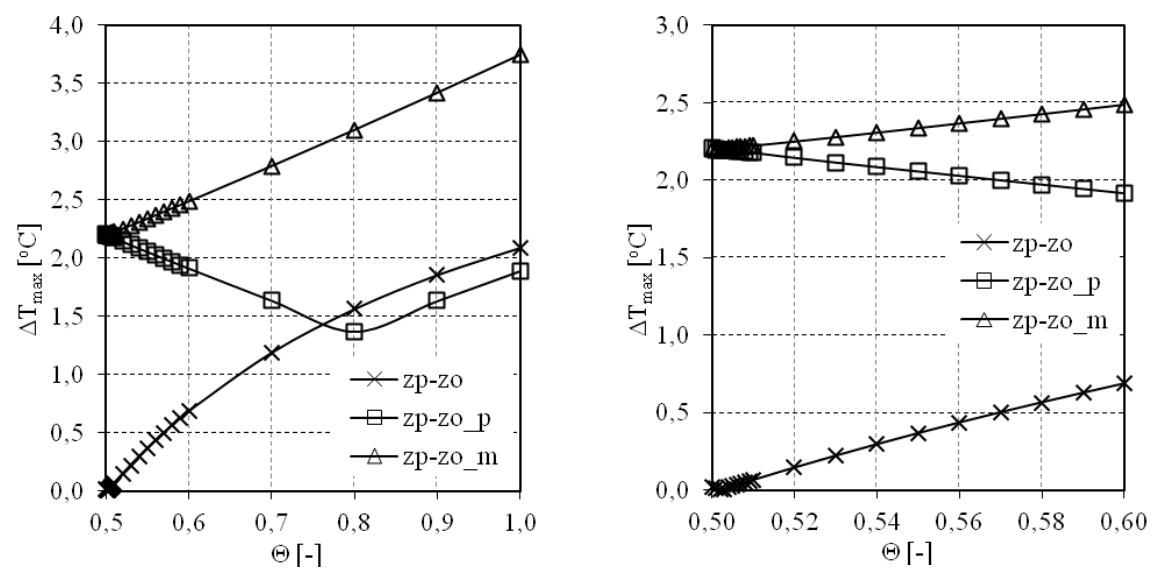

Rys. 6. Maksymalna różnica pomiędzy rozkładem temperatury na brzegu walca obliczona na podstawie rozwiązania zagadnienia prostego (zp) i zagadnienia odwrotnego przy uwzględnieniu błędu położenia termoelementu (zo_p, zo_m) dla $\beta=1,5 ; \mathrm{t}=680 \mathrm{~s} ; \mathrm{r}_{\mathrm{z}}=50 \mathrm{~mm}$, termoelementu umieszczonego w odległości g $=2 \mathrm{~mm}$ od brzegu oraz dla $\Theta \in[0,5 ; 1]$ (z lewej); $\Theta \in[0,5 ; 0,6]$ (po prawej)

Fig. 6. The maximum difference between the distribution of temperature on the edge of the cylinder calculated on the basis of solving the direct problem (zp) and the inverse problem with the error of the thermocouple location (zo_p,zo_m) for $\beta=1.5 ; \mathrm{t}=680 \mathrm{~s} ; \mathrm{r}_{\mathrm{z}}=50 \mathrm{~mm}$, the thermocouple located $g=2 \mathrm{~mm}$ from the edge and for $\Theta \in[0,5 ; 1]$ (left) $\Theta \in[0,5 ; 0,6]$ (right)

Wrażliwość rozwiązania równania macierzowego $A \chi=B$ na nieprecyzyjne umieszczenie termoelementu (błąd zabudowy) i stochastyczny błąd pomiaru temperatury w znacznym stopniu zależy od wartości $\Theta$. Przy występowaniu losowego błędu pomiaru temperatury dla $\Theta=0,5$ maksymalny błąd wyznaczonej temperatury na brzegu elementu $\Delta T_{\max }$ wyniósł powyżej $120{ }^{\circ} \mathrm{C}$, natomiast dla $\Theta=0,52 \Delta T_{\max } \approx 25^{\circ} \mathrm{C}$.

\section{Podsumowanie}

W pracy przedstawiono rozwiązanie zagadnienia odwrotnego równania przewodnictwa ciepła dla geometrii cylindrycznej. Badano wpływ parametru $\Theta$ (w całkowaniu splotu) na różnicę rozkładów tempratury na brzegu walca założonego w zagadnieniu prostym i obliczonego z zastosowaniem zagadnienia odwrotnego. Analizowano również wpływ parametru całkowania $\Theta$ na wrażliwość otrzymywanych wyników. Uwzględniono błąd zabudowy termoelementu oraz stochastyczny błąd pomiaru temperatury w walcu. $\mathrm{Na}$ podstwie przeprowadzonych badań wynika, że odpowiedni dobór wartości $\Theta$ 
podczas całkowania numerycznego powoduje uzyskanie rozwiązania słabo wrażliwego na zaburzenia danych pomiarowych.

a)

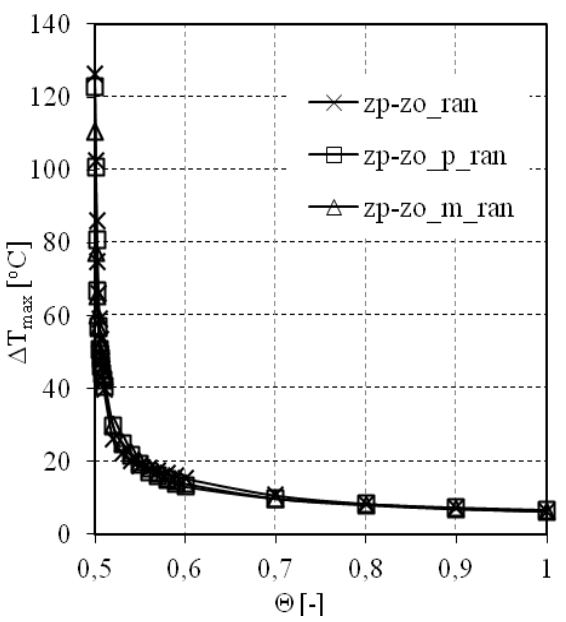

b)

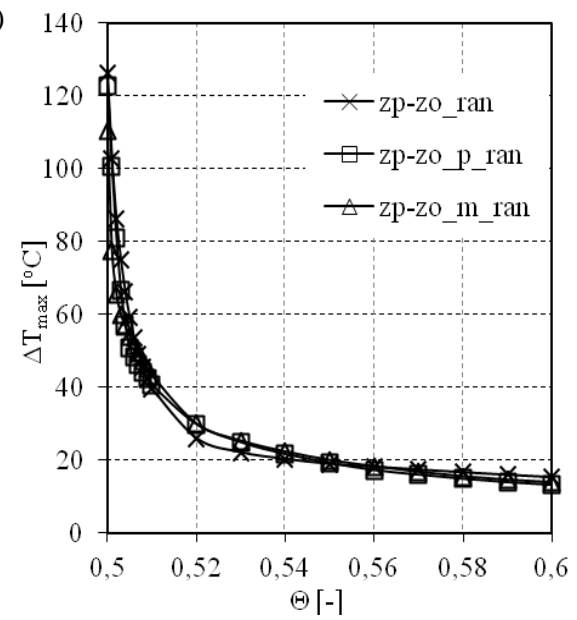

c)

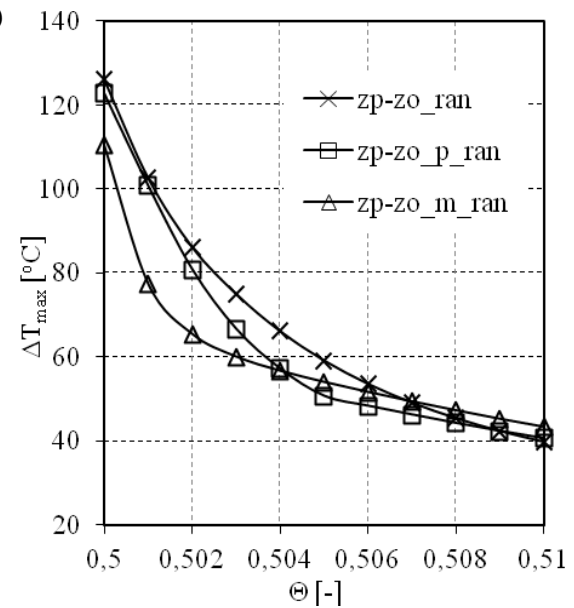

Rys. 7. Maksymalna różnica pomiędzy rozkładem temperatury na brzegu walca obliczonym na podstawie rozwiązania zagadnienia prostego (zp) i zagadnienia odwrotnego przy uwzględnieniu błędu położenia termoelementu i losowego zaburzenia temperatury (zo_p_ran, zo_m_ran) dla $\beta=$ 1,$5 ; \mathrm{t}=680 \mathrm{~s} ; \mathrm{r}_{\mathrm{z}}=50 \mathrm{~mm}$, termoelementu umieszczonego $\mathrm{w}$ odległości $\mathrm{g}=2 \mathrm{~mm}$ od brzegu oraz a) $\Theta \in[0,5 ; 1]$ b) $\Theta \in[0,5 ; 0,6]$ c) $\Theta \in[0,5 ; 0,51]$

Fig. 7. The maximum difference between the distribution of temperature on the edge of the cylinder calculated on the basis of solving the direct problem (zp) and the inverse problem with the error of the thermocouple location and random disturbance of temperature (zo_p_ran, zo_m_ran) for $\beta=1.5 ; \mathrm{t}=680 \mathrm{~s} ; \mathrm{r}_{\mathrm{z}}=50 \mathrm{~mm}$, the thermocouple located $\mathrm{g}=2 \mathrm{~mm}$ from the edge and a) $\Theta \in[0,5 ; 1]$ b) $\Theta \in[0,5 ; 0,6]$ c) $\Theta \in[0,5 ; 0,51]$ 


\section{Literatura}

[1] Björck A., Dahlquist G.: Metody numeryczne, PWN, Warszawa 1983.

[2] Ciałkowski M.: Sekwencyjna i globalna metoda rozwiązania zagadnienia odwrotnego dla równania przewodnictwa ciepła, XIII Sympozjum Wymiany Ciepła i Masy, 2007.

[3] Ciałkowski M.: Wybrane metody i algorytmy rozwiązywania zagadnienia odwrotnego dla równania przewodnictwa ciepła, Wydawnictwo Politechniki Poznańskiej, Poznań 1996.

[4] Ciałkowski M., Grysa K.: A sequential and global method of solving an inverse problem of heat conduction equation, J. Theor. Applied Mech., 48 (2010) 111-134.

[5] Ciałkowski M.J., Grysa K.W.: On a Certain Inverse Problem of Temperature and Thermal Stress Fields, Acta Mechanica 36 (1980) 169-185.

[6] Duda P.: Eksperymentalna weryfikacja metody rozwiązywania odwrotnego problemu przewodzenia ciepła, ZN PRz 290, Mechanika, 86 (2014) 191-198.

[7] Guz E., Kącki E.: Pola temperatury w ciałach stałych, PWN, Warszawa 1967.

[8] Chen H-T., Wu X-Y.: Investigation of heat transfer coefficient in twodimensional transient inverse heat conduction problems using the hybrid inverse scheme, Int. J. Numer. Meth. Engng., 73 (2008) 107-122.

[9] Joachimiak M., Ciałkowski M.: Optimal choice of integral parameter in a process of solving the inverse problem for heat equation, Arch. Thermodyn., 35 2014) 265280.

[10] Joachimiak M., Ciałkowski M.: Stabilna metoda rozwiązania brzegowego zagadnienia odwrotnego dla niestacjonarnego równania przewodnictwa ciepła, rozdział w: Analiza systemów energetycznych, pod redakcją: B. Węglowskiego i P. Dudy, Wydawnictwo Politechniki Krakowskiej, Kraków 2013.

[11] Kącki E., Siewierski L.: Wybrane działy matematyki wyższej z ćwiczeniami, PWN, Warszawa 1985.

[12] McLachlan N.W.: Funkcje Bessela dla inżynierów, PWN, Warszawa 1964.

[13] Sokała M.: Metoda analityczno-numeryczna rozwiązywania zagadnień przewodnictwa ciepła z zastosowaniem funkcji cieplnych i operacji odwrotnych, praca doktorska, Politechnika Poznańska, Poznań 2004.

[14] Taler J., Duda P.: Rozwiązywanie prostych i odwrotnych zagadnień przewodzenia ciepła, WNT, Warszawa 2003.

[15] Taler J., Zima W.: Solution of inverse heat conduction problems using control volume approach, Int. J. Heat Mass Transfer, 42 (1999) 1123-1140.

[16] Wiśniewski S.: Pomiary temperatury w badaniach silników i urządzeń cieplnych, WNT, Warszawa 1983. 


\section{SOLUTION OF THE INVERSE PROBLEM WITH NUMERICAL INTEGRATION OF CONVOLUTION}

\section{S u m m a r y}

An inverse problem for the linear unsteady heat conduction equation in a cylinder was solved in this paper. The solution was obtained using the Laplace transform and was presented as a convolution of functions. To integrate the convolution the parameter $\Theta$ was used. The influence of the value of this parameter on the sensitivity of the solution of inverse problem was examined. The influence of the error of thermocouple installation and the stochastic error of temperature measurement on the error of temperature distribution on the cylinder edge was taken into account during the tests.

Keywords: inverse problem, heat conduction, sensitivity of solution

DOI: $10.7862 / \mathrm{rm} .2015 .31$

Otrzymano/received: $24.03 .2015 \mathrm{r}$.

Zaakceptowano/accepted: $22.06 .2015 \mathrm{r}$. 